\title{
Role of transcription factor Sp1 in the quercetin-mediated inhibitory effect on human malignant pleural mesothelioma
}

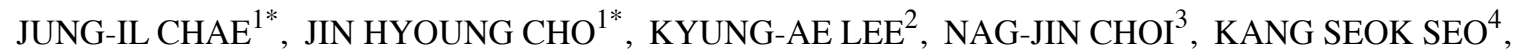 \\ SANG-BUM KIM ${ }^{5}$, SANG-HAN LEE ${ }^{2}$ and JUNG-HYUN SHIM ${ }^{2}$ \\ ${ }^{1}$ Department of Dental Pharmacology, School of Dentistry, Brain Korea 21 Project, Chonbuk National University, \\ Jeonju 561-756; ${ }^{2}$ Department of Biochemistry, College of Medicine, Soonchunhyang University, Cheonan 330-090; \\ ${ }^{3}$ Department of Animal Science, College of Agricultural and Life Science, Chonbuk National University, Jeonju 561-756; \\ ${ }^{4}$ Department of Animal Science and Technology, Sunchon National University, Suncheon 540-742; \\ ${ }^{5}$ Animal Genomics and Bioinformatics Division, National Institute of Animal Science, \\ Rural Development Administration (RDA), Suwon 441-706, Republic of Korea
}

Received April 19, 2012; Accepted May 25, 2012

DOI: 10.3892/ijmm.2012.1075

\begin{abstract}
Quercetin (Qu) is found in plants, including red onions and in the skins of red apples, and induces the apoptosis of certain malignant cells. However, no report has been issued on the apoptotic effect of Qu on human malignant pleural mesothelioma. In the present study, it was found that MSTO- $211 \mathrm{H}$ mesothelioma cell viability was reduced and apoptotic cell death was increased by $\mathrm{Qu}(20-80 \mu \mathrm{M})$, which was found to have an $\mathrm{IC}_{50}$ of $58 \mu \mathrm{M}$. In addition, Qu increased the sub- $\mathrm{G}_{1}$ cell population, and was found to interact with specificity protein 1 (Sp1) and significantly suppressed its expression at the protein and mRNA levels. Furthermore, Qu modulated the levels of Sp1 regulatory genes, such as cyclin D1, myeloid cell leukemia (Mcl)-1 and survivin in MSTO-211H cells. Apoptotic signaling cascades were activated by the cleavage of Bid, caspase- 3 and PARP, and by the downregulation of Bcl-xL and the upregulation of Bax in MSTO-211H cells. Our results strongly suggest that Sp1 be considered as a novel molecular target of $\mathrm{Qu}$ in human malignant pleural mesothelioma.
\end{abstract}

\section{Introduction}

Quercetin (Qu) [2-(3,4-dihydroxyphenyl)-3,5,7-trihydroxy4H-1-benzopyran-4-one] belongs to an extensive class of polyphenolic flavonoid compounds ubiquitous in plants and

Correspondence to: Professor Jung-Hyun Shim, Department of Biochemistry, College of Medicine, Soonchunhyang University, Ssangyong-dong, Seobuk-gu, Cheonan, Choongnam 331-090, Republic of Korea

E-mail: s1004jh@gmail.com

*Contributed equally

Key words: quercetin, apoptosis, specificity protein 1, human malignant pleural mesothelioma, anticancer plant food sources. $\mathrm{Qu}$ is a beneficial chemical compound widely dispersed in the human diet. Accordingly, high concentrations of $\mathrm{Qu}$ are found in onions $(391.0 \mathrm{mg} / \mathrm{kg})$, broccoli $(74.5 \mathrm{mg} / \mathrm{kg})$, apples $(50 \mathrm{mg} / \mathrm{kg})$ and beans $(11.0 \mathrm{mg} / \mathrm{kg})(1)$ and intakes between 6 and $31 \mathrm{mg} /$ day have been reported (2). $\mathrm{Qu}$ has been used as a dietary supplement for many years, and thus, its use does not raise concerns as regards its toxicity. Of note, when $\mathrm{Qu}$ was discovered it was believed to be a mutagen, but subsequent studies showed it to be a powerful natural anticancer agent (3). The exact mechanism behind the cancer preventive effect of Qu remians unknown, yet the majority of studies have indicated that its anti-inflammatory and antioxidant properties may be responsible for the beneficial effects (4). Although the link between Qu and cancer has been established in controlled scientific settings, its efficacy in the treatment of cancer in humans is currently unknown.

Human malignant pleural mesothelioma is a rare tumor; however, its incidence is increasing and it has a poor prognosis $(5,6)$. Thus, knowledge of the mechanism of mesothelial carcinogenesis is required to support efforts to develop targeted treatments.

Specificity protein ( $\mathrm{Sp}$ ) is an ubiquitously expressed transcription factor belonging to a family of 8 transcription factors (7), which are ubiquitously expressed in a variety of mammalian cells (8). Furthermore, $\mathrm{Spl}$ is highly expressed in a number of cancer tissues, such as pancreatic, thyroid, colorectal, breast, hepatocellular, prostate, gastric cancer and lung cancer $(7,9)$. Sp1 was one of the first eukaryotic transactivators to be identified (10). Sp1 proteins have been defined as Sp/Kruppel-like transcription factors (11), and a previous study showed that Sp1 plays an important role in the carcinogenesis and metastasis of human tumors by regulating growth-related signal transductions, apoptosis, tumor suppressor genes, cell cycle control molecules, oncogenes and angiogenesis-related factors $(12,13)$.

$\mathrm{Qu}$ is an important dietary flavonoid, found in various vegetables, fruits, seeds, nuts, tea and red wine (14). Qu has been shown to have diverse biological activities, including antiinflammatory and antitumor properties (15-17). Furthermore, 
$\mathrm{Qu}$ has been shown to have various beneficial effects, such as antioxidant, cardioprotective, anti-inflammatory and antitumor effects (18). However, the antitumor mechanisms involved and the molecular targets of Qu have not been identified, especially in human malignant pleural mesothelioma. Accordingly, in the present study, we investigated the apoptotic effect of $\mathrm{Qu}$ on a human malignant pleural mesothelioma cell line. Our results suggest that $\mathrm{Qu}$ be considered as a drug or natural supplement candidate for the prevention of malignant pleural mesothelioma.

\section{Materials and methods}

Materials. HyClone RPMI-1640 medium and fetal bovine serum (FBS) were obtained from Thermo Scientific (Logan, UT). The following antibodies were used: 4'-6-diamidino2-phenylindole (DAPI), propidium iodide (PI), anti-Sp1 (1C6), anti-poly (ADP-ribose) polymerase (PARP) (BD Biosciences, San Diego, CA), anti-cyclin D1 (M-20), anti-myeloid cell leukemia (Mcl)-1, anti-survivin, anti-Bid, anti-Bax, antiBcl-xL (Cell Signaling Technology, Inc., Danvers, MA), anti-caspase-3 (H-277) (Santa Cruz Biotechnology, Inc., Santa Cruz, CA) and anti- $\beta$-actin (AC-74) (Sigma-Aldrich, Inc. St. Louis, MO). RNase A was supplied by Sigma-Aldrich.

Cell culture. MSTO-211H cells were obtained from the American Tissue Culture Collection (Manassas, VA). Cells were maintained in RPMI-1640 medium supplemented with 5\% FBS and $100 \mathrm{U} / \mathrm{ml}$ each of penicillin and streptomycin at $37^{\circ} \mathrm{C}$ in a $5 \% \mathrm{CO}_{2}$ incubator.

MTS assay. The effects of Qu on cell viability were determined using a 3-(4,5-dimethylthiazol-2-yl)-5-(3-carboxymethoxyphenyl)-2-(4-sulfophenyl)-2H-tetrazolium (MTS) assay kit (Promega, Madison, WI). MSTO-211H cells were seeded in a 96-well plate for $24 \mathrm{~h}$ and treated with $\mathrm{Qu}(20-80 \mu \mathrm{M})$ for 24 or $48 \mathrm{~h}$. MTS solution was then added for $2 \mathrm{~h}$ at $37^{\circ} \mathrm{C}$ in $5 \%$ $\mathrm{CO}_{2}$. The absorbance at $490 \mathrm{~nm}$ was recorded using a GloMaxMulti Microplate Multimode Reader (Promega).

DAPI staining. The level of nuclear condensation and fragmentation was observed by nucleic acid staining with DAPI. MSTO-211H cells were treated with $\mathrm{Qu}$, harvested by trypsinization, and fixed in $100 \%$ methanol at room temperature for $20 \mathrm{~min}$. The cells were spread on slides, stained with DAPI solution $(2 \mu \mathrm{g} / \mathrm{ml})$, and analyzed under a FluoView confocal laser microscope (Fluoview FV10i; Olympus Corporation, Tokyo, Japan).

PI staining. Following treatment with $\mathrm{Qu}(20-80 \mu \mathrm{M})$ for $72 \mathrm{~h}$, the detached MSTO-211H cells (floaters) were collected by centrifugation and combined with adherent cells. The cells were fixed with $70 \%$ ice-cold ethanol overnight at $-20^{\circ} \mathrm{C}$, and subsequently treated with $150 \mathrm{mg} / \mathrm{ml} \mathrm{RNase} \mathrm{A} \mathrm{and} 20 \mathrm{mg} / \mathrm{ml}$ PI. DNA contents were analyzed by flow cytometry using a MACSQuant Analyzer (Miltenyi Biotec $\mathrm{GmbH}$, Bergisch Gladbach, Germany).

Western blot analysis. MSTO-211H cells treated with Qu (20-80 $\mu \mathrm{M}$ ) for $48 \mathrm{~h}$ were washed with phosphate-buffered saline (PBS), and were then homogenized with PRO-PREP ${ }^{\mathrm{TM}}$
Protein Extraction Solution (Intron Biotechnology, Korea). Extracted proteins were measured using DC protein assay reagent (Bio-Rad Laboratories Inc., Hercules, CA). The equal amounts of protein samples were separated by $12 \%$ SDS-polyacrylamide gel electrophoresis and then transferred onto membranes, which were blocked for $2 \mathrm{~h}$ at room temperature with 5\% non-fat dried milk in PBS containing $0.05 \%$ Tween-20, and then incubated overnight at $4^{\circ} \mathrm{C}$ with specific antibodies. The protein bands were observed after treating them with horseradish peroxidase-conjugated secondary antibody using a Pierce ECL Western Blotting Substrate (Thermo Scientific, Rockford, IL).

In vitro EGCG-sepharose $4 B$ pull-down assays. This method has been described previously $(19,20)$. Briefly, MSTO-211H cell lysates were reacted with sepharose $4 \mathrm{~B}$ beads or $\mathrm{Qu}-$ sepharose $4 \mathrm{~B}$ beads in reaction buffer $(50 \mathrm{mM}$ Tris, $\mathrm{pH} \mathrm{7.5,}$ $5 \mathrm{mM}$ EDTA, $150 \mathrm{mM} \mathrm{NaCl}, 1 \mathrm{mM}$ dithiothreitol, $0.01 \%$ Nonidet P-40, $2 \mu \mathrm{g} / \mathrm{ml}$ bovine serum albumin, $0.02 \mathrm{mM}$ phenylmethylsulfonyl fluoride and $1 \mathrm{X}$ proteinase inhibitor), and washed 5 times with washing buffer $(50 \mathrm{mM}$ Tris, $\mathrm{pH} 7.5,5 \mathrm{mM}$ EDTA, $150 \mathrm{mM} \mathrm{NaCl}, 1 \mathrm{mM}$ dithiothreitol, $0.01 \%$ Nonidet P-40, $0.02 \mathrm{mM}$ phenylmethylsulfonyl fluoride). Proteins bound to the beads were analyzed by western blot analysis using anti-Sp1 antibody.

Reverse transcription-polymerase chain reaction (RT-PCR). Total RNA was extracted from the cells using TRIzol ${ }^{\circledR}$ Reagent (Life Technologies, Carlsbad, CA), and $2 \mu \mathrm{g}$ of RNA were used to synthesize cDNA using the HelixCript ${ }^{\mathrm{TM}}$ firststrand cDNA synthesis kit (NanoHelix, Korea). cDNA was obtained by PCR amplification using $\beta$-actin-specific and Sp1-specific primers (as described below) using the following PCR conditions: 25 cycles of $1 \mathrm{~min}$ at $95^{\circ} \mathrm{C}, 1 \mathrm{~min}$ at $60^{\circ} \mathrm{C}$ and $1 \mathrm{~min}$ at $72^{\circ} \mathrm{C}$. The $\beta$-actin primers used were: forward, 5'-GTG-GGG-CGC-CCC-AGG-CAC-CA-3' and reverse, 5'-CTC-CTT-AAT-GTC-ACG-CAC-GAT-TTC-3'; and the Sp1 primers were: forward, ATG CCT AAT ATT CAG TAT CAA GTA and reverse, CCC TGA GGT GAC AGG CTG TGA. PCR products were analyzed by $2 \%$ agarose gel electrophoresis.

Luciferase assay for cyclin D1, Mcl-1 and survivin transactivation. MSTO-211H cells $\left(6 \times 10^{4}\right)$ were added to each well of a 24 -well plate and incubated at $37^{\circ} \mathrm{C}$ in a humidified atmosphere of $5 \% \mathrm{CO}_{2}$ for $24 \mathrm{~h}$. Transient transfection was performed using Lipofectamine 2000 reagent (Invitrogen, Carlsbad, CA). The survivin-269 promoter construct was kindly provided by Dr Sung-Dae Cho (Chonbuk National University, Jeonju, Korea). The Mcl-1 promoter was obtained from Addgene (Cambridge, MA). Cells were transfected with 250 ng of cyclin D1 (-1745-luc), Mcl-1 (-325-luc), or survivin $(-269-\mathrm{luc})$ and $20 \mathrm{ng}$ of $\beta$-gal using Lipofectamine 2000 reagent (Invitrogen) for $24 \mathrm{~h}$ (21). After cafestol and kahweol treatment for $48 \mathrm{~h}$, the cells were disrupted with $100 \mathrm{ml}$ of lysis buffer [0.1 M potassium phosphate ( $\mathrm{pH} 7.8), 1 \%$ Triton X-100, $1 \mathrm{mM}$ dithiothreitol (DTT), $2 \mathrm{mM}$ EDTA], and firefly luciferase activity and galactosidase were determined with a Promega luciferase assay kit according to the manufacturer's instructions. Relative luciferase units were calculated by normalizing to the galactosidase activity. 
A<smiles></smiles>

C $\mathrm{Qu}(\mu \mathrm{M})$
B
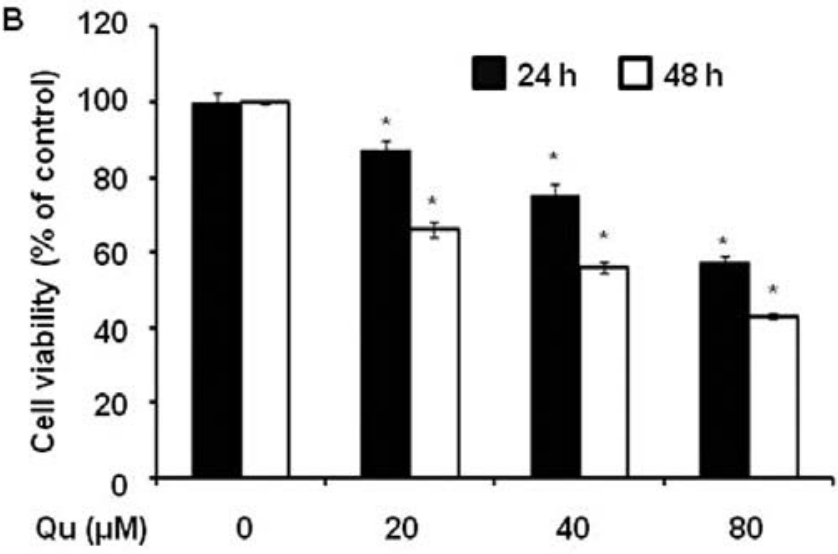

20
80

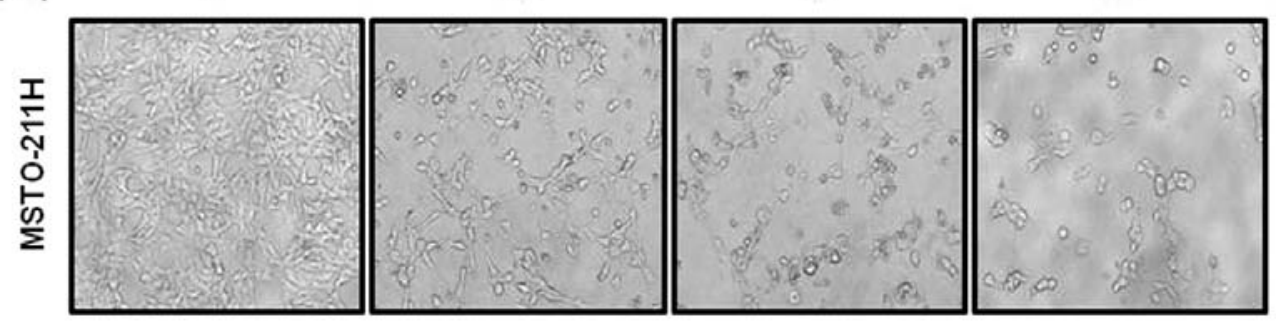

Figure 1. The effect of quercetin (Qu) on MSTO-211H cell viability. (A) Chemical structure of Qu. (B) The effect of Qu on the viability of MSTO-211H cells. MSTO-211H cells $\left(3 \times 10^{3}\right.$ cells/200 $\left.\mu \mathrm{l}\right)$ were treated with Qu (20-80 $\left.\mu \mathrm{M}\right)$ in 5\% FBS-RPMI-1640 for various amounts of time. Cell viabilities were estimated using MTS assay kits, as described in Materials and methods. Results are cell viabilities relative to untreated cells, and represent 3 independent experiments. Data are presented as the means $\pm \mathrm{SD}$. The asterisk indicates a significant difference compared with the control ( $\mathrm{P}<0.05)$. (C) Morphological changes observed in MSTO-211H cells treated or not treated with Qu $(20-80 \mu \mathrm{M})$ for $48 \mathrm{~h}$.

Statistical analysis. The results are presented as the means \pm SD of at least 3 independent experiments performed in triplicate. Data were analyzed for statistical significance using one-way analysis of variance. A P-value $<0.05$ was considered to indicate a statistically significant difference.

\section{Results}

$Q u$ reduces the viability of $M S T O-211 H$ cells. To evaluate the effects of Qu (Fig. 1A) on the viability of malignant mesothelioma cells we used a MTS assay. It was found that Qu suppressed cell viability with an $\mathrm{IC}_{50}$ of $58 \mu \mathrm{M}$ in MSTO-211H cells for $48 \mathrm{~h}$ (Fig. 1B). Qu treatment also resulted in a significant concentration-dependent inhibition of cell growth with $\mathrm{IC}_{50}$ values of approximately $73 \mu \mathrm{M}$ in HT28 cells (another malignant mesothelioma cell line) for $48 \mathrm{~h}$ (data not shown). To investigate the morphological changes, MSTO-211H cells were treated with various concentrations $(20-80 \mu \mathrm{M})$ of $\mathrm{Qu}$ for $48 \mathrm{~h}$. The results obtained showed that the cells had decreased in size and that they had became rounded (Fig. 1C).

$Q u$ induces the apoptosis of MSTO-211H cells. The effect of $\mathrm{Qu}$ treatment on the initiation of apoptosis in MSTO-211H cells was determined by nuclear morphology using DAPI staining. The Qu treatment of mesothelioma cells increased nuclear condensation and fragmentation when compared to the control group (Fig. 2A). In order to evaluate whether the increase in the sub- $\mathrm{G}_{1}$ cell population induced by $\mathrm{Qu}$ was related to apoptosis, the Qu-treated cells were used for PI staining. The number of MSTO- $211 \mathrm{H}$ cells in the sub- $\mathrm{G}_{1}$ phase increased from 25 to $50 \%$ in the presence of $20-80 \mu \mathrm{M} \mathrm{Qu}$ (Fig. 2B and C).

$Q u$ regulates $\mathrm{Sp1}$ protein levels in MSTO-211H cells. Sp1 contributes to cell progression and apoptotic cell death via the regulation of the expression of a number of genes, such as cyclin D1, Mcl-1, survivin, Bcl-xL, Bax and caspase-3 in various cancers $(7,13,22)$. The interaction between $\mathrm{Sp} 1$ and Qu was examined by conducting a Qu-sepharose 4B affinity experiment by immunoblotting with anti-Sp1. The results obtained indicated that Qu bound with $\mathrm{Sp} 1$ in cell lysates from human MSTO-211H cells (Fig. 3A). Furthermore, we found that Qu at 20, 40 and $80 \mu \mathrm{M}$ downregulated Sp1 protein (Fig. 3D) and mRNA levels (Fig. 3B), and Sp1 protein expression level monitoring showed that $\mathrm{Qu}$ time-dependently reduced protein levels over 0 to $48 \mathrm{~h}$ (Fig. 3C). Qu clearly attenuated the cyclin D1, Mcl-1 and survivin promoter activities (Fig. 4A-C). In addition, significant decreases in the protein levels of cyclin D1, Mcl-1 and survivin were observed following Qu treatment (Fig. 4D).

$Q u$ regulates the expression of anti-apoptotic and apoptotic molecules in MSTO-211H cells. The treatment of cells with $\mathrm{Qu}$ regulated the expression levels of several apoptosis-related proteins. MSTO-211H cells were treated with various concentrations $(20-80 \mu \mathrm{M})$ of $\mathrm{Qu}$ for $48 \mathrm{~h}$ and harvested. The protein expression levels of Bid, Bcl-xL, caspase-3, PARP and Bax were analyzed by western blot analysis. The results showed 
A

Qu $(\mu M) \quad 0$
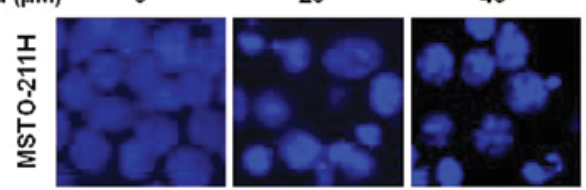

B

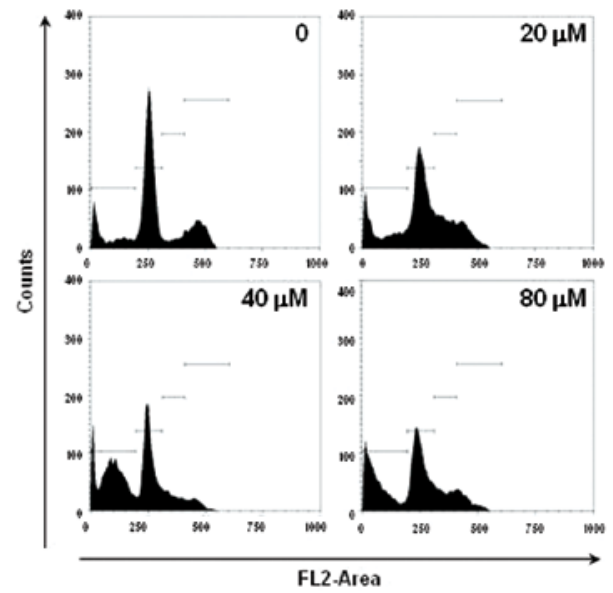

80

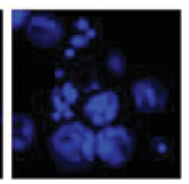

C

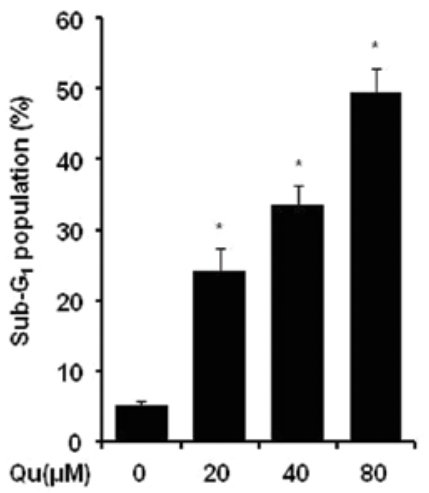

Figure 2. The apoptotic effect of quercetin (Qu) on MSTO-211H cells. (A) Cells were treated or not (DMSO) with Qu (20, 40 or $80 \mu \mathrm{M})$ for $48 \mathrm{~h}$. The cells were harvested and prepared for DAPI staining and PI staining as described in Materials and methods. (B) Analysis of DNA fragmentation and nuclear condensation by fluorescence microscopy (magnification, x600) after Qu treatment. (C) DNA fragmentation and nuclear condensation were quantified. The results are from triplicate experiments and are expressed as the means \pm SD. Representative histograms of the sub-G $\mathrm{G}_{1}$ population. Qu-treated cells were compared with the untreated cells. The results shown are the averages of 3 independent experiments performed in triplicate. The asterisk indicates a significant difference compared with the control ("P<0.05).

A

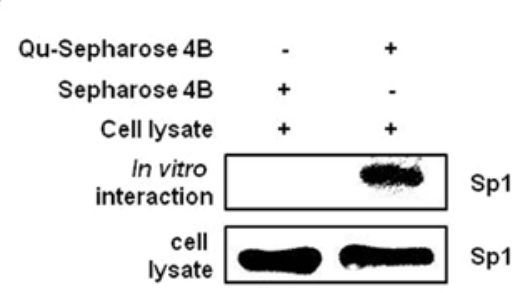

B
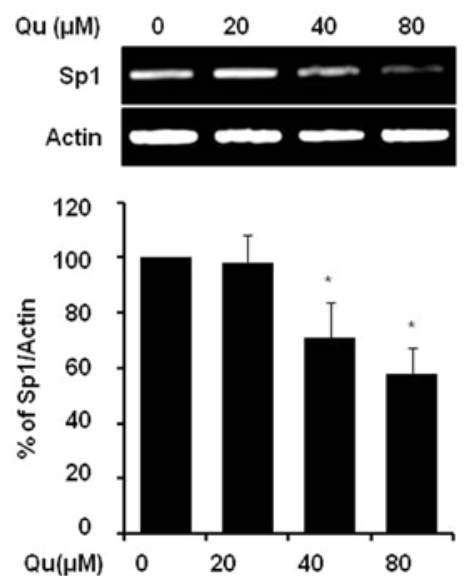

C

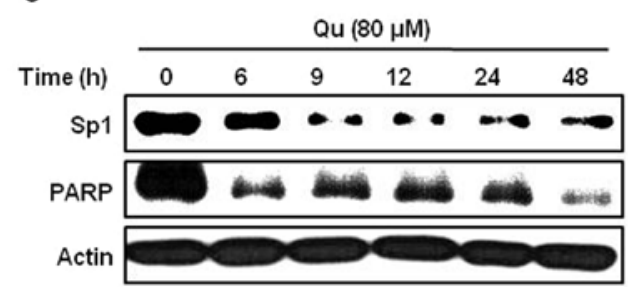

D
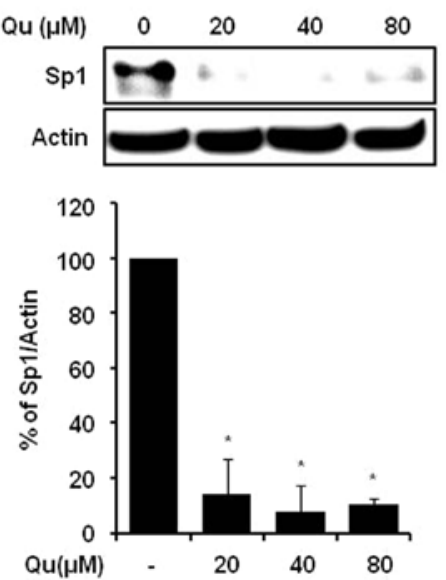

Figure 3. Quercetin (Qu) bound with specificity protein 1 (Sp1) and suppressed Sp1 protein levels. (A) Qu bound with Sp1 ex vivo. The ex vivo binding of Qu with Sp1 from MSTO-211H cell lysates was confirmed by pull-down assay using Qu-sepharose 4B beads and subsequent western blot analysis. (B) The effect of Qu treatment $(20-80 \mu \mathrm{M})$ for $48 \mathrm{~h}$ on Sp1 mRNA expression was determined by RT-PCR. The graphs indicate the ratio of Sp1 to actin expression. (C) Time-dependent effects of Qu on Sp1 and PARP protein expression levels were investigated in MSTO-211H cells treated with Qu (20-80 $\mu \mathrm{M})$ for 0, 6, 9, 12, 24 or $48 \mathrm{~h}$. (D) The effect of Qu treatment $(20-80 \mu \mathrm{M})$ for $48 \mathrm{~h}$ on Sp1 protein expression was determined by western blot analysis. Actin was used to ensure equal protein loadings. The data shown are the means \pm SD of 3 independent experiments. The asterisks indicate a significant decrease in Spl protein expression in Qu-treated cells compared with the untreated cells ( $\left.{ }^{*} \mathrm{P}<0.05\right)$. 
A

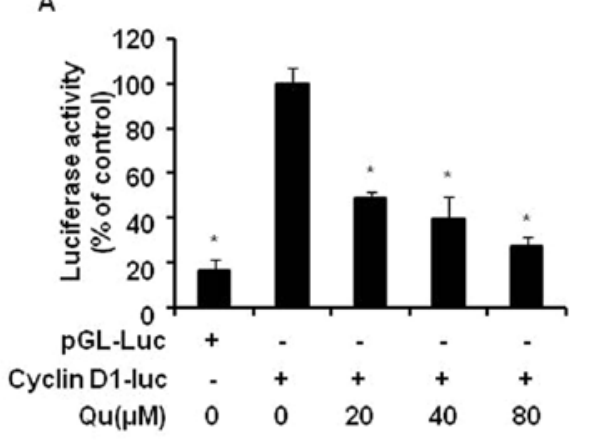

C

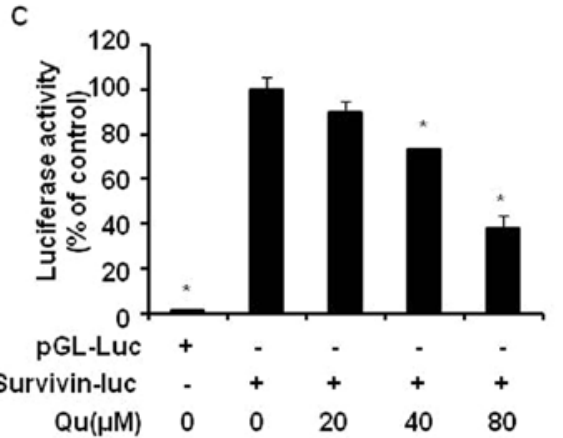

B

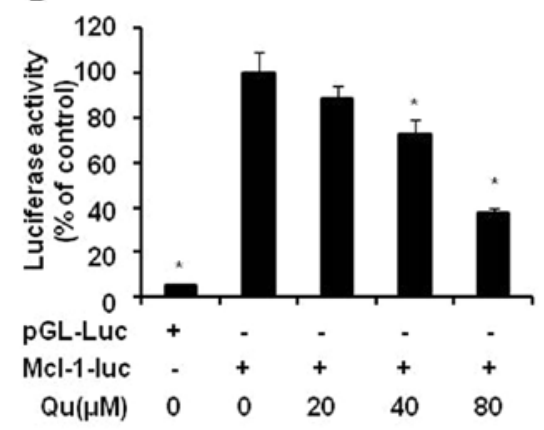

D

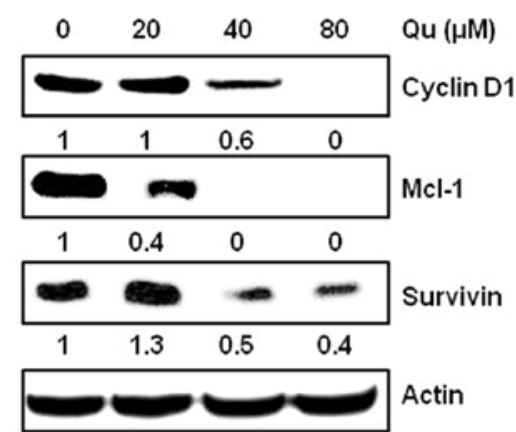

Figure 4. The effect of quercetin (Qu) on specificity protein 1 (Sp1) downstream target proteins. The firefly luciferase (A) cyclin D1, (B) Mcl-1 or (C) survivin reporter gene activity was assessed. For the reporter gene assay, MSTO-211H cells were transfected with a plasmid mixture containing the cyclin D1, Mcl-1, or survivin luciferase reporter gene $(250 \mathrm{ng})$ and the $\beta$-gal gene $(20 \mathrm{ng})$ for normalization. At $24 \mathrm{~h}$ after transfection, cells were treated with various concentrations of $\mathrm{Qu}$ for $48 \mathrm{~h}$. Results are shown as the means $\pm \mathrm{SD}$ of 3 independent experiments. The asterisks indicate a significant change relative to the $\mathrm{Qu}$-treated cells compared with the untreated cells ("P $<0.05)$. (D) MSTO-211H cells were treated with Qu $(20-80 \mu \mathrm{M})$ for $48 \mathrm{~h}$, and the protein expressions of cyclin D1, Mcl-1, and survivin were determined by western blot analysis. A total of $40 \mu \mathrm{g}$ of cellular extract per lane was separated on a $12 \%$ SDS-PAGE gel as described in Materials and methods. Equal protein loading and protein transfer were confirmed with anti-actin antibody.

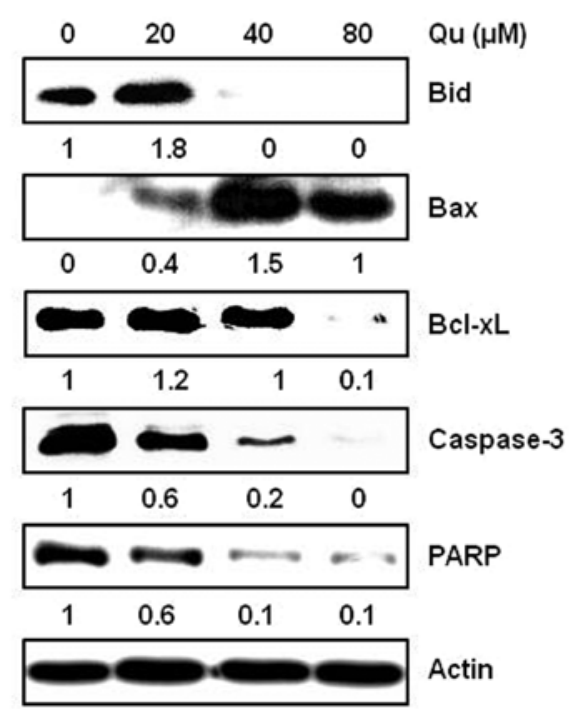

Figure 5. The apoptotic effect of quercetin $(\mathrm{Qu})$ on MSTO-211H cells. The MSTO- $211 \mathrm{H}$ cells were treated with $\mathrm{Qu}(20-80 \mu \mathrm{M})$ for $48 \mathrm{~h}$, and the protein expressions of Bid, Bcl-xL, caspase-3, PARP and Bax were determined by western blot analysis. A total of $40 \mu \mathrm{g}$ of cellular extract per lane was separated on a $12 \%$ SDS-PAGE gel as described in Materials and methods. Equal protein loading and protein transferwere confirmed with anti-actin antibody.

that $\mathrm{Qu}$ induced the activation of Bid, caspase-3 and PARP, decreased Bcl-xL, and increased Bax levels in the MSTO-211H cells (Fig. 5).

\section{Discussion}

Malignant pleural mesothelioma and the majority of lung carcinomas are diagnosed at an advanced stage, conferring a poor prognosis $(23,24)$. The incidence of malignant pleural mesothelioma is rising rapidly in many countries and it continues to be a challenging clinical problem. Our results showed that $\mathrm{Qu}$ has potential as a chemopreventive and chemotherapeutic agent for malignant pleural mesothelioma and that Sp1 is a potential therapeutic target of Qu.

It has previously been reported that the $\mathrm{Sp} 1$ protein is overexpressed in many human tumors (25) and cancer cell lines (26-30) and a number of studies have reported that $\mathrm{Spl}$ is highly expressed in a variety of human tumors, such as those of the pancreas, colon, lung, breast and prostate (9), demonstrating that the use of natural compounds may be used to inhibit Sp1 expression in cancer. Advances in treatment regimens have only had modest effects, although gene therapy offers a novel therapeutic approach, and has been evaluated in a number of clinical trials. Strategies include the induction of apoptosis, cytokinebased therapy, suicide gene expression, tumor suppressor gene replacement, various vaccination approaches, and the adoptive transfer of modified immune cells. A number of studies have considered the clinical results, limitations and future directions of gene therapy trials for thoracic malignancies $(23,24)$.

Various plants and fruits have been reported to have cancer chemopreventive properties, and thus, investigators have sought to identify new active phytochemicals (31). Qu is an ubiquitous 
dietary flavonoid that has recently been described as a potential anticancer agent (32) due to its ability to modulate cell proliferation, survival and differentiation, targeting key molecules responsible for tumor cell growth $(33,34)$.

However, the mechanisms responsible for the antitumor activity of $\mathrm{Qu}$ are not yet fully understood. The induction of apoptosis may be one of the mechanisms as Qu has antiproliferative effects $(35,36)$ and can induce death via apoptosis in leukemia (37), breast (38), hepatoma (39), oral (40) and colon (35) cancer cells. However, no previous study has been conducted on the effect of $\mathrm{Qu}$ on human mesothelioma cells. In this study, to the best of our knowledge, we demonstrate for the first time that Qu induces apoptotic cell death by inhibiting $\mathrm{Sp} 1$ protein expression in a time- and dose-dependent manner in MSTO-211H cells.

Previous studies have identified other flavonoids as having similar effects as Qu. For example, mithramycin A is one of the older chemotherapy drugs, and is known to suppress the expression of $\mathrm{Sp} 1$, to inhibit $\mathrm{Sp} 1$ binding and to inhibit the transcription of c-myc, p27, p21, cyclin D1, Mcl-1 and survivin selectively $(13,41-43)$. Remarkably, our results indicate that $\mathrm{Qu}$ directly binds to $\mathrm{Sp1}$, and possibly prevents the binding of Spl by G-C rich promoters. Our data provide evidence that $\mathrm{Qu}$ inhibits Sp1 expression at the protein and mRNA levels. Transcriptional response targeting genes containing the Sp1 binding site in their promoters are involved in a number of cellular functions ranging from differentiation to cell cycle progression, proliferation and apoptotic cell death (7). Our results showed that $\mathrm{Qu}$ suppressed $\mathrm{Sp1}$ downstream target genes, including cyclin D1, Mcl-1 and survivin in MSTO-211H cells by promoter assay and western blot analyses. The apoptotic effect of Qu on MSTO-211H cells was found to be induced via the inhibition of $\mathrm{Sp} 1$ protein expression in vitro. Our results from in vitro experiments show that the Sp1 protein is a major factor of the antitumor effects of $\mathrm{Qu}$ in mesothelioma.

In conclusion, the results from the present study suggest that $\mathrm{Qu}$ has therapeutic and chemopreventative benefits and that $\mathrm{Sp} 1$ be considered a therapeutic target in malignant pleural mesothelioma and other advanced-stage cancers. Furthermore, our data suggest that $\mathrm{Qu}$ be considered a drug or natural supplement candidate for the prevention of malignant pleural mesothelioma.

\section{Acknowledgements}

This study was supported by the Basic Science Research program through the National Research Foundation Korea (NRF) Funded by the Ministry of Education, Science and Technology (2012-0003226, 2010-0021532), and the NextGeneration BioGreen 21 Program (PJ008116062011), Rural Development Administration, Republic of Korea.

\section{References}

1. Miean KH and Mohamed S: Flavonoid (myricetin, quercetin, kaempferol, luteolin, and apigenin) content of edible tropical plants. J Agric Food Chem 49: 3106-3112, 2001.

2. Kim GN and Jang HD: Protective mechanism of quercetin and rutin using glutathione metabolism on $\mathrm{HO}$-induced oxidative stress in HepG2 cells. Ann NY Acad Sci 1171: 530-537, 2009.
3. Hirpara KV, Aggarwal P, Mukherjee AJ, Joshi N and Burman AC: Quercetin and its derivatives: synthesis, pharmacological uses with special emphasis on anti-tumor properties and prodrug with enhanced bio-availability. Anticancer Agents Med Chem 9: 138-161, 2009.

4. Wang L, Tu YC, Lian TW, Hung JT, Yen JH and Wu MJ: Distinctive antioxidant and antiinflammatory effects of flavonols. J Agric Food Chem 54: 9798-9804, 2006.

5. Jakobsen JN and Sorensen JB: Review on clinical trials of targeted treatments in malignant mesothelioma. Cancer Chemother Pharmacol 68: 1-15, 2011.

6. Toyokuni S: Mechanisms of asbestos-induced carcinogenesis Nagoya J Med Sci 71: 1-10, 2009.

7. Li L and Davie JR: The role of Sp1 and Sp3 in normal and cancer cell biology. Ann Anat 192: 275-283, 2010.

8. Kong LM, Liao CG, Fei F, Guo X, Xing JL and Chen ZN: Transcription factor $\mathrm{Spl}$ regulates expression of cancer-associated molecule CD147 in human lung cancer. Cancer Sci 101: 1463-1470, 2010.

9. Sankpal UT, Goodison S, Abdelrahim M and Basha R: Targeting Spl transcription factors in prostate cancer therapy. Med Chem 7: 518-525, 2011.

10. Archer MC: Role of $s p$ transcription factors in the regulation of cancer cell metabolism. Genes Cancer 2: 712-719, 2011.

11. Wan J, Carr BA, Cutler NS, Lanza DL, Hines RN and Yost GS: Sp1 and Sp3 regulate basal transcription of the human CYP2F1 gene. Drug Metab Dispos 33: 1244-1253, 2005.

12. Bai $X$ and Deng H: Research progress on relationship between transcription factor Spl and tumor. Zhejiang Da Xue Xue Bao Yi Xue Ban 39: 215-220, 2010 (In Chinese).

13. Culver C, Melvin A, Mudie S and Rocha S: HIF-1alpha depletion results in SP1-mediated cell cycle disruption and alters the cellular response to chemotherapeutic drugs. Cell Cycle 10: 1249-1260, 2011

14. Gibellini L, Pinti M, Nasi M, et al: Quercetin and cancer chemoprevention. Evid Based Complement Alternat Med 2011: 591356, 2011.

15. Linsalata M, Orlando A, Messa C, Refolo MG and Russo F: Quercetin inhibits human DLD-1 colon cancer cell growth and polyamine biosynthesis. Anticancer Res 30: 3501-3507, 2010.

16. Russo M, Spagnuolo C, Volpe S, Mupo A, Tedesco I and Russo GL: Quercetin induced apoptosis in association with death receptors and fludarabine in cells isolated from chronic lymphocytic leukaemia patients. Br J Cancer 103: 642-648, 2010.

17. Thangasamy T, Sittadjody S, Mitchell GC, et al: Quercetin abrogates chemoresistance in melanoma cells by modulating deltaNp73. BMC Cancer 10: 282, 2010.

18. Gonzalez-Gallego J, Garcia-Mediavilla MV, Sanchez-Campos S and Tunon MJ: Fruit polyphenols, immunity and inflammation. Br J Nutr 104 (Suppl 3): S15-S27, 2010.

19. Shim JH, Choi HS, Pugliese A, et al: (-)-Epigallocatechin gallate regulates $\mathrm{CD} 3$-mediated $\mathrm{T}$ cell receptor signaling in leukemia through the inhibition of ZAP-70 kinase. J Biol Chem 283: 28370-28379, 2008.

20. Zykova TA, Zhu F, Zhai X, et al: Resveratrol directly targets COX-2 to inhibit carcinogenesis. Mol Carcinog 47: 797-805, 2008

21. Choi ES, Shim JH, Jung JY, et al: Apoptotic effect of tolfenamic acid in androgen receptor-independent prostate cancer cell and xenograft tumor through specificity protein 1 . Cancer Sci 102: 742-748, 2011.

22. Shim JH, Shin JA, Jung JY, et al: Chemopreventive effect of tolfenamic acid on KB human cervical cancer cells and tumor xenograft by downregulating specificity protein 1 . Eur J Cancer Prev 20: 102-111, 2011.

23. Vachani A, Moon E, Wakeam E and Albelda SM: Gene therapy for mesothelioma and lung cancer. Am J Respir Cell Mol Biol 42: 385-393, 2010.

24. Vachani A, Moon E, Wakeam E, Haas AR, Sterman DH and Albelda SM: Gene therapy for lung neoplasms. Clin Chest Med 32: 865-885, 2011.

25. Choi ES, Cho SD, Jeon JG and Cho NP: The apoptotic effect of the hexane extract of Rheum undulatum L. in oral cancer cells through the down-regulation of specificity protein 1 and survivin. Lab Anim Res 27: 19-24, 2011.

26. Chiefari E, Brunetti A, Arturi F, et al: Increased expression of AP2 and Sp1 transcription factors in human thyroid tumors: a role in NIS expression regulation? BMC Cancer 2: 35, 2002.

27. Hosoi Y, Watanabe T, Nakagawa $\mathrm{K}$, et al: Up-regulation of DNA-dependent protein kinase activity and Sp1 in colorectal cancer. Int J Oncol 25: 461-468, 2004. 
28. Wang L, Wei D, Huang S, et al: Transcription factor Sp1 expression is a significant predictor of survival in human gastric cancer. Clin Cancer Res 9: 6371-6380, 2003.

29. Yao JC, Wang L, Wei D, et al: Association between expression of transcription factor Sp1 and increased vascular endothelial growth factor expression, advanced stage, and poor survival in patients with resected gastric cancer. Clin Cancer Res 10: 4109-4117, 2004

30. Zannetti A, Del Vecchio S, Carriero MV, et al: Coordinate up-regulation of Sp1 DNA-binding activity and urokinase receptor expression in breast carcinoma. Cancer Res 60: 1546-1551, 2000.

31. Shukla Y and George J: Combinatorial strategies employing nutraceuticals for cancer development. Ann NY Acad Sci 1229: $162-175,2011$.

32. Zamin LL, Filippi-Chiela EC, Dillenburg-Pilla P, Horn F, Salbego C and Lenz G: Resveratrol and quercetin cooperate to induce senescence-like growth arrest in C6 rat glioma cells. Cancer Sci 100: 1655-1662, 2009.

33. Murakami A, Ashida $\mathrm{H}$ and Terao J: Multitargeted cancer prevention by quercetin. Cancer Lett 269: 315-325, 2008.

34. Ranelletti FO, Maggiano N, Serra FG, et al: Quercetin inhibits p21-RAS expression in human colon cancer cell lines and in primary colorectal tumors. Int J Cancer 85: 438-445, 2000.

35. van Erk MJ, Roepman P, van der Lende TR, et al: Integrated assessment by multiple gene expression analysis of quercetin bioactivity on anticancer-related mechanisms in colon cancer cells in vitro. Eur J Nutr 44: 143-156, 2005.

36. Watson WH, Cai J and Jones DP: Diet and apoptosis. Annu Rev Nutr 20: 485-505, 2000.
37. Shen SC, Chen YC, Hsu FL and Lee WR: Differential apoptosis-inducing effect of quercetin and its glycosides in human promyeloleukemic HL-60 cells by alternative activation of the caspase 3 cascade. J Cell Biochem 89: 1044-1055, 2003.

38. Singhal RL, Yeh YA, Praja N, Olah E, Sledge GW Jr and Weber G: Quercetin down-regulates signal transduction in human breast carcinoma cells. Biochem Biophys Res Commun 208: 425-431, 1995.

39. Chi YS, Jong HG, Son KH, Chang HW, Kang SS and Kim HP: Effects of naturally occurring prenylated flavonoids on enzymes metabolizing arachidonic acid: cyclooxygenases and lipoxygenases. Biochem Pharmacol 62: 1185-1191, 2001.

40. Ong CS, Tran E, Nguyen TT, et al: Quercetin-induced growth inhibition and cell death in nasopharyngeal carcinoma cells are associated with increase in Bad and hypophosphorylated retinoblastoma expressions. Oncol Rep 11: 727-733, 2004.

41. Blume SW, Snyder RC, Ray R, Thomas S, Koller CA and Miller DM: Mithramycin inhibits SP1 binding and selectively inhibits transcriptional activity of the dihydrofolate reductase gene in vitro and in vivo. J Clin Invest 88: 1613-1621, 1991.

42. Chintharlapalli S, Papineni S, Lei P, Pathi S and Safe S: Betulinic acid inhibits colon cancer cell and tumor growth and induces proteasome-dependent and -independent downregulation of specificity proteins (Sp) transcription factors. BMC Cancer 11: 371, 2011.

43. Pietrzak $M$ and Puzianowska-Kuznicka M: p53-dependent repression of the human MCL-1 gene encoding an anti-apoptotic member of the BCL-2 family: the role of Spl and of basic transcription factor binding sites in the MCL-1 promoter. Biol Chem 389: 383-393, 2008. 